\title{
Possible Inhibitory Effect of Lipid Peroxides on Acid Lipase Activity via Low-Density Lipoprotein in Human Mononuclear Leukocytes
}

\author{
Fusako MaEhIRA, ${ }^{1, *}$ Ikuko MiYAGI, ${ }^{1}$ Shinzoh KoHno, ${ }^{2}$ \\ and Fukuichi NAKADA, ${ }^{3}$ \\ ${ }^{1}$ Department of Biochemistry for Health Science, ${ }^{2}$ The Second \\ Department of Adult Health, School of Health Sciences, \\ ${ }^{3}$ The First Department of Biochemistry, School of \\ Medicine, Faculty of Medicine, University of \\ The Ryukyus, Nishihara, Okinawa 903-01, Japan
}

(Received June 10, 1991)

\begin{abstract}
Summary Acid lipase (AL) activity was measured in mononuclear leukocytes (MNL) isolated from 214 subjects. An inverse relation was observed between the AL activity and serum cholesterol (CHO) with age variation: The age groups above 30 , which showed low AL activities in their MNL, exhibited high serum CHO; whereas the 20-to-29 age group, which had the highest AL activity among the age groups, showed the lowest $\mathrm{CHO}$ value. Moreover, the hypercholesterolemic group with high apo-B levels showed significantly low AL activity in both sexes when compared with the normolipidemic group. Significant negative correlations were also observed in the hypercholesterolemic group between the AL activity and both $\mathrm{CHO}$ and apo-B, and between the AL activity and lipid peroxides (LPO). On the other hand, while the addition of lowdensity lipoprotein (LDL) from patients with type II hypercholesterolemia to the AL assay system and the culture medium of MNL resulted in the inhibition of the AL activity, the inhibitory effect was prevented by preincubation of LDL with anti apo-B serum. These data suggest a certain regulatory mechanism of $\mathrm{LDL}$, the physiological substrate of $\mathrm{AL}$, on the AL activity; this action possibly occurs through lipid peroxides in LDL.
\end{abstract}

Key Words: acid lipase, low-density lipoprotein, lipid peroxides, mononuclear leukocytes, hypercholesterolemia

*To whom correspondence should be addressed. 
Lysosomal acid lipase plays an important role in the intracellular metabolism of exogenous LDL-associated cholesterol esters (E-CHO), and the genetic deficiency of AL is associated with intracellular accumulation of E-CHO and triglycerides (TG) in various organs of affected patients [1, 2]. Hypercholesterolemia, in which the cell are provided with an increased amount of LDLassociated $\mathrm{E}-\mathrm{CHO}$, is established as a major risk factor for atherosclerosis and related occlusive vascular diseases $[3,4]$. Since the monocyte-derived macrophages are considered to be a possible progenitor of foam cells in atherosclerotic plaques [5] and since there is a decreased AL activity in MNL from patients with type II hypercholesterolemia $[6,7]$, the reduced AL activity is suggestive of a risk factor in the development of premature atherosclerosis.

We previously reported that there was a reversible inhibitory effect of apo-Bcarrying lipoproteins isolated from hypercholesterolemic rabbits on AL derived from normolipidemic rabbits and that the inhibition was blocked in vitro by anti apo-B serum [8]. In the present study, in order to elucidate the regulatory mechanism on AL in relation to blood lipids, AL activity was measured in MNL isolated from 214 subjects, and the results were confirmed by in vitro inhibition experiments on the enzyme and by a cell culture study.

\section{MATERIALS AND METHODS}

Subjects. Individuals who had fasted for at least $15 \mathrm{~h}$ were selected from among inhabitants of Yonashiro-Son, which is located in the central part of Okinawa Island, at the time of their annual health examinations. They were divided into a normal group and a hypercholesterolemic group. The normal group included 166 individuals (63 males and 103 females) with normal laboratory tests. The hypercholesterolemic group consisted of 48 individuals (11 males and 37 females) with serum cholesterol levels above $250 \mathrm{mg} / \mathrm{dl}$ and included 11 hypertensive subjects with systolic pressure above $160 \mathrm{mmHg}$ and diastolic pressure above 90. Patients with type IIa or IIb hypercholesterolemia who were seen in the out-patient clinic of the University of the Ryukyus Hospital were free of other complications that would affect lipid metabolism.

Preparation of samples. For the population study of the AL activity, the MNL were isolated from $1 \mathrm{ml}$ of heparinized blood, and AL was extracted from the cell pellets by $0.1 \%$ Triton $\mathrm{X}-100$ as described previously [8]. The human lipoprotein fractions were prepared by discontinuous gradient ultracentrifugation at $4^{\circ} \mathrm{C}$ and $40,000 \mathrm{rpm}$ for $48 \mathrm{~h}$, and the purity of the concentrated fractions was examined electrophoretically [8].

Biochemical analyses. The AL assay was fully described in the previous study [8]. In brief, labeled cholesterol esters at a final concentration of $5 \mathrm{~mm}$ were incubated with the enzyme sources for $2 \mathrm{~h}$ at $37^{\circ} \mathrm{C}$ and $\mathrm{pH} 4.5$ in the presence of $1 \mathrm{~mm} \beta$-mercaptoethanol, $1 \mathrm{~mm}$ EDTA, and $0.1 \%$ Triton $\mathrm{X}-100$; the fatty acids thereby produced were extracted by the solvent system according to Belfrage and 
Vaughan [9]. One unit of enzyme activity was defined as that amount of enzyme catalyzing the release of $1 \mathrm{nmol}$ of fatty acid per hour. In the inhibition study, the substrate was premixed with $10 \mu 1$ of lipoproteins and the reaction was started by the addition of a $20-\mu 1$ sample. In the experiment for preventing the inhibitory effect of lipoprotein, 2 or $4 \mu 1$ of diluted anti-human apo-B goat serum (titer, 4.8 $\mathrm{mg} / \mathrm{ml}$; Daiichi Kagaku, Tokyo) was preincubated with $10 \mu 1$ of lipoproteins in the antigen vs. antibody ratios as indicated in Table 3 for $2 \mathrm{~h}$ at $4^{\circ} \mathrm{C}$, followed by the addition of the substrate and the enzyme extract prepared from the MNL of a normolipidemic subject.

Lipid peroxides were measured fluorometrically as thiobarbituric acid reactive substances (TBA) by the method of Yagi [10]. Lipids in sera and lipoproteins were measured manually by use of commercial kits employing enzymatic procedures. Protein was determined by the Folin-Lowry method [11].

Cell culture. The MNL (85-95\% lymphocytes and 5-15\% monocytes) isolated from a normolipidemic subject were incubated for $72 \mathrm{~h}$ in RMPI 1640 medium containing penicillin $(100 \mathrm{U} / \mathrm{ml})$, streptomycin $(100 \mu \mathrm{g} / \mathrm{ml})$, and $5 \mathrm{mg} /$ $\mathrm{ml}$ human lipoprotein-deficient serum in a humidified $5 \% \mathrm{CO}_{2}$ incubator at $37^{\circ} \mathrm{C}$ at a final cell concentration of about $2 \times 10^{5} / \mathrm{ml}$. The cells were then washed with the medium, resuspended in the same, and plated out in 24-well cluster plates with the addition of $1 \mathrm{ml}$ of cell suspension containing about $2 \times 10^{5}$ cells to each well. LDL isolated from patients with type II hypercholesterolemia was added next to make the indicated concentration in the presence or absence of various concentrations of chloroquine, and the cells were then further incubated for $6 \mathrm{~h}$. After that the cells were washed three times with cold phosphate-buffered saline (PBS), and extracted with $0.1 \%$ Triton X-100 in PBS.

Other methods. Subjects were judged to be obese who had a body weight of more than $75 \%$ of the average body weight, which was set as the theoretical $50 \%$ value, of the population group of the same sex, age, and height. This was based on the "Table for Judging Obesity for Japanese" which was determined from 21,530 adults over age 20. The table was published by the Ministry of Public Health Welfare of Japan on August 22, 1986. The significance of correlation coefficients was tested by the two-sided $t$-test.

\section{RESULTS}

All data represent the mean values of duplicate or triplicate determinations.

\section{Relation of $A L$ activity to serum cholesterol}

An inverse relation was observed between the AL activity and the serum CHO levels with age variation: The age group above 30 , which showed low AL activity in their MNL, exhibited high serum CHO; whereas the 20-to-29 age group, which had the highest AL activity of all age the groups, showed the lowest $\mathrm{CHO}$ values (Table 1). The AL activity in the hypercholesterolemic group with high apo-B 


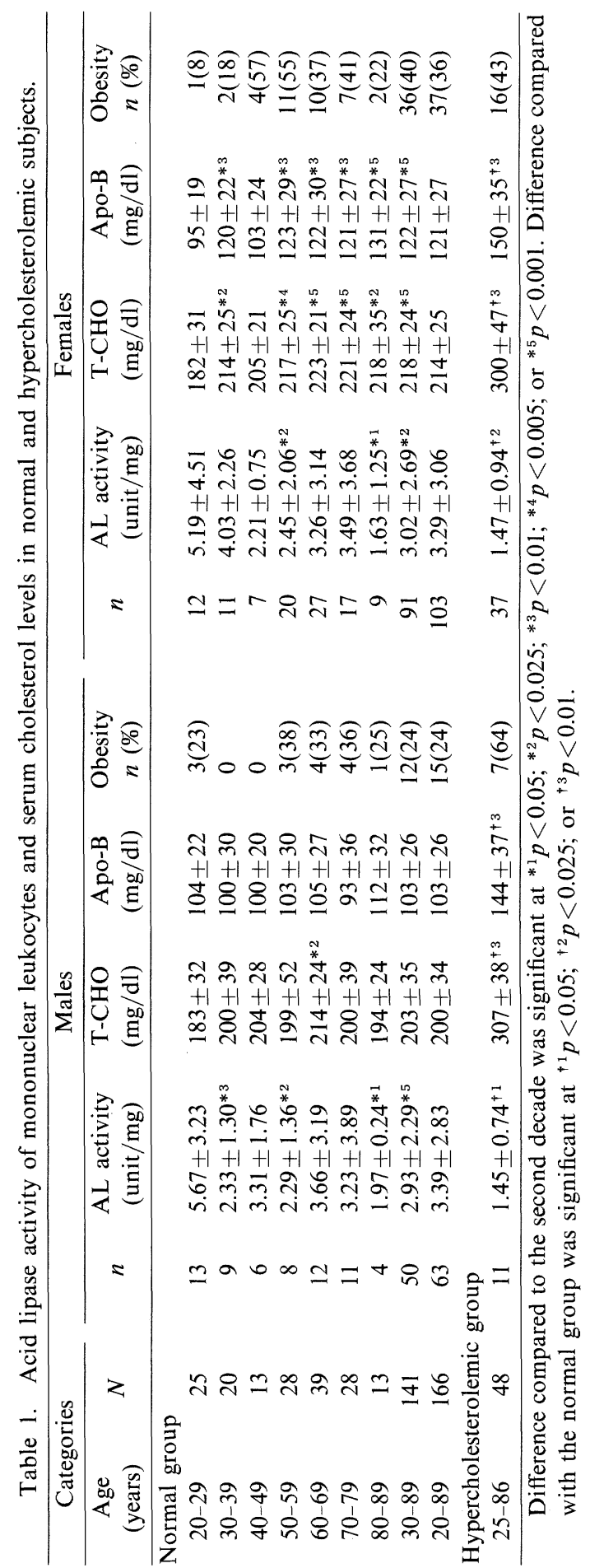



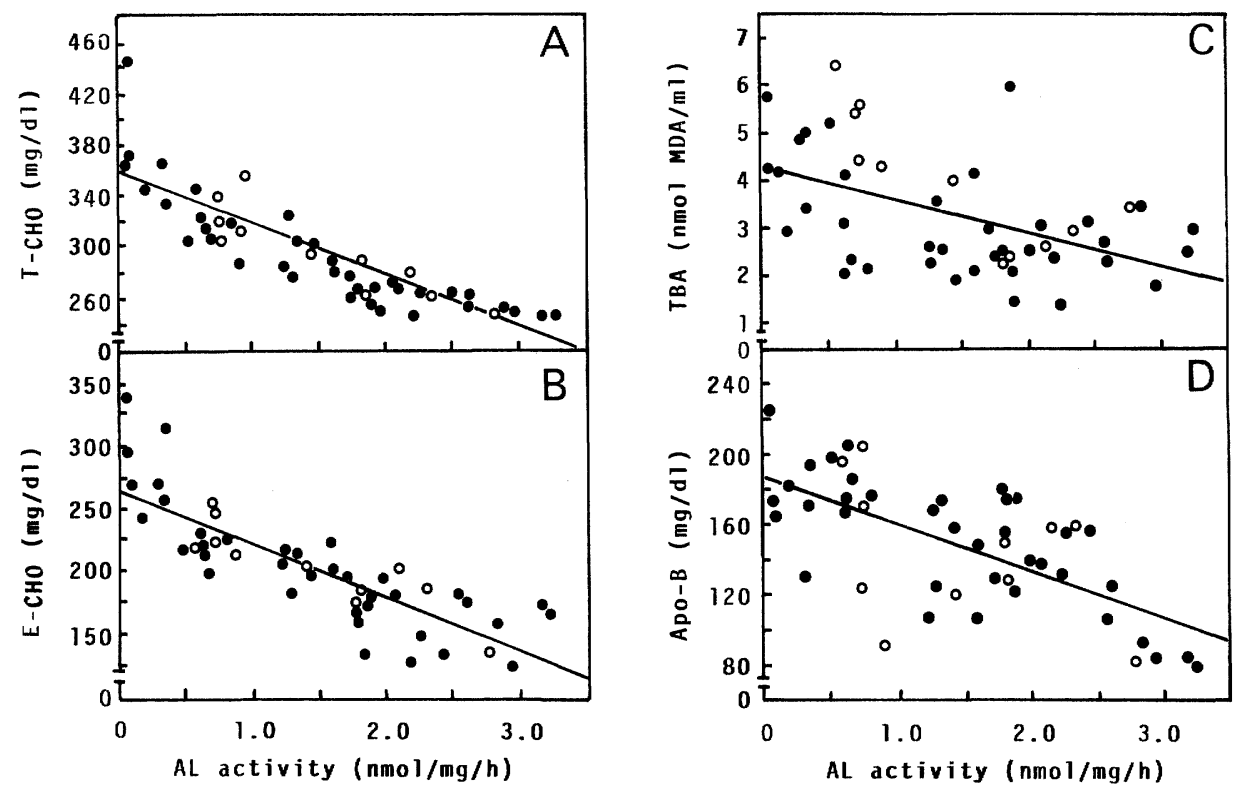

Fig. 1. Linear regression of T-CHO (A), E-CHO (B), TBA (C), and apo-B (D) on the AL activity in the hypercholesterolemic group. The open and closed symbols represent male and female, respectively. Correlation coefficients and $p$ value are presented in Table 2 .

Table 2. Correlations between the acid lipase activity in mononuclear leukocytes and various parameters of plasma cholesterol metabolism in the hypercholesterolemic group.

\begin{tabular}{|c|c|c|c|c|c|c|c|}
\hline \multicolumn{2}{|c|}{ Parameters } & \multicolumn{2}{|c|}{ Total $(n=48)$} & \multicolumn{2}{|c|}{ Males $(n=11)$} & \multicolumn{2}{|c|}{ Females $(n=37)$} \\
\hline$x$ & $y$ & $r$ & $p$ & $r$ & $p$ & $r$ & $p$ \\
\hline \multirow[t]{4}{*}{$\overline{\mathrm{AL}}$ activity } & T-CHO & -0.812 & $<0.001$ & -0.544 & NS & -0.864 & $<0.001$ \\
\hline & E-CHO & -0.831 & $<0.001$ & -0.875 & $<0.001$ & -0.827 & $<0.005$ \\
\hline & Apo-B & -0.673 & $<0.001$ & -0.413 & NS & -0.745 & $<0.001$ \\
\hline & TBA & -0.510 & $<0.001$ & -0.804 & $<0.005$ & -0.469 & $<0.005$ \\
\hline \multirow[t]{2}{*}{$\mathrm{T}-\mathrm{CHO}$} & Apo-B & +0.592 & $<0.001$ & +0.443 & NS & +0.644 & $<0.005$ \\
\hline & TBA & +0.494 & $<0.001$ & +0.833 & $<0.005$ & +0.520 & $<0.001$ \\
\hline
\end{tabular}

NS, not significant.

levels was significantly lower than the average value in the normal group taken as a whole. Significant negative correlations were also observed between the AL activity and both the $\mathrm{CHO}$ and apo-B levels, and between the AL activity and TBA values in the hypercholesterolemic group (Fig. 1). The $r$ and $p$ values are presented in Table 2 . TBA values were $3.52 \pm 1.03$ for males $(n=54)$ and $2.72 \pm 1.07$ for females $(n=80)$ in the normal group, whereas they were $3.96 \pm 1.37$ for males $(n=11)$ and $3.04 \pm 1.14$ for females $(n=37)$ in the hypercholesterolemic group. The TBA values were significantly higher in males than in females in both the normal group $(p<0.001)$ and the hypercholesterolemic group $(p<0.05)$, and they were ca.

Vol. 11, No. 2, 1991 


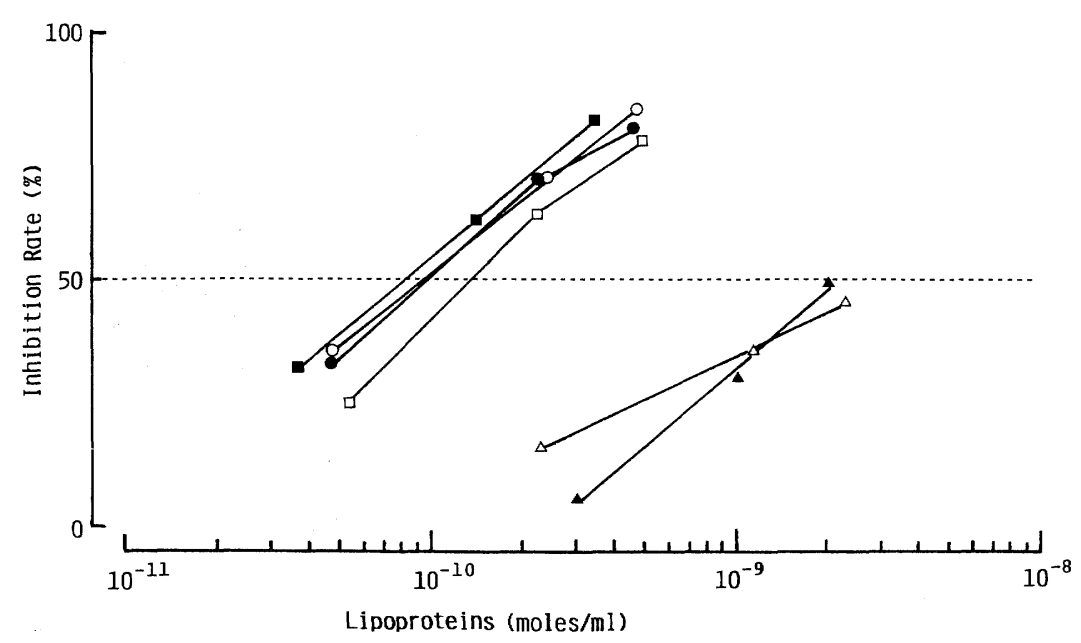

Fig. 2. The inhibitory effect of lipoproteins on AL activity. The percentage of inhibition was calculated based on the control activity of 12.3 units $/ \mathrm{mg}$. The moles per $\mathrm{ml}$ of lipoproteins added, which were isolated from patients with type IIa (closed symbols) and type IIb (open symbols) hypercholesterolemia, were calculated, assuming estimated molecular weights of $6.0 \times 10^{6}, 2.2 \times 10^{5}$, and $2.5 \times 10^{5}$ for VLDL (squares), LDL (circles), and HDL (triangles), respectively.

$10 \%$ higher in the hypercholesterolemic group than in the normal group for both sexes, but the difference was not significant.

\section{Effect of lipoproteins on AL activity}

Addition of lipoproteins isolated from patients with hypercholesterolemia to the assay system inhibited the AL activity, and the apo-B-carrying lipoproteins were ca. 150 times more potent than high-density lipoprotein (HDL) when compared at the $50 \%$ inhibition point (Fig. 2). The inhibition caused by apo-Bcarrying lipoproteins was prevented by preincubation of the lipoproteins with anti apo-B serum prior to the enzyme assay, but the anti-serum showed no effect on the inhibition that was observed following the addition of HDL in large concentration (Table 3).

\section{Cell culture study of the effect of lipoproteins on the AL activity}

There was a dose-dependent chloroquine inhibition of the lysosomal AL activity of MNL, in which the inhibition was reduced by the presence of $15 \mu \mathrm{g} /$ $\mathrm{ml}$ LDL; but the effect of LDL disappeared at $100 \mu \mathrm{M}$ chloroquine. Chloroquine inhibited the AL activity not only in the intact cells but also directly in the cell-free extract (Fig. 3 (A), (C)). Addition of LDL isolated from hypercholesterolemic serum to the culture media inhibited the AL activity at concentrations above $15 \mu \mathrm{g} / \mathrm{ml}$ in the absence of chloroquine pertaining to both oleate and linoleate esters as substrates; thus the inhibited fraction represented catalytic 


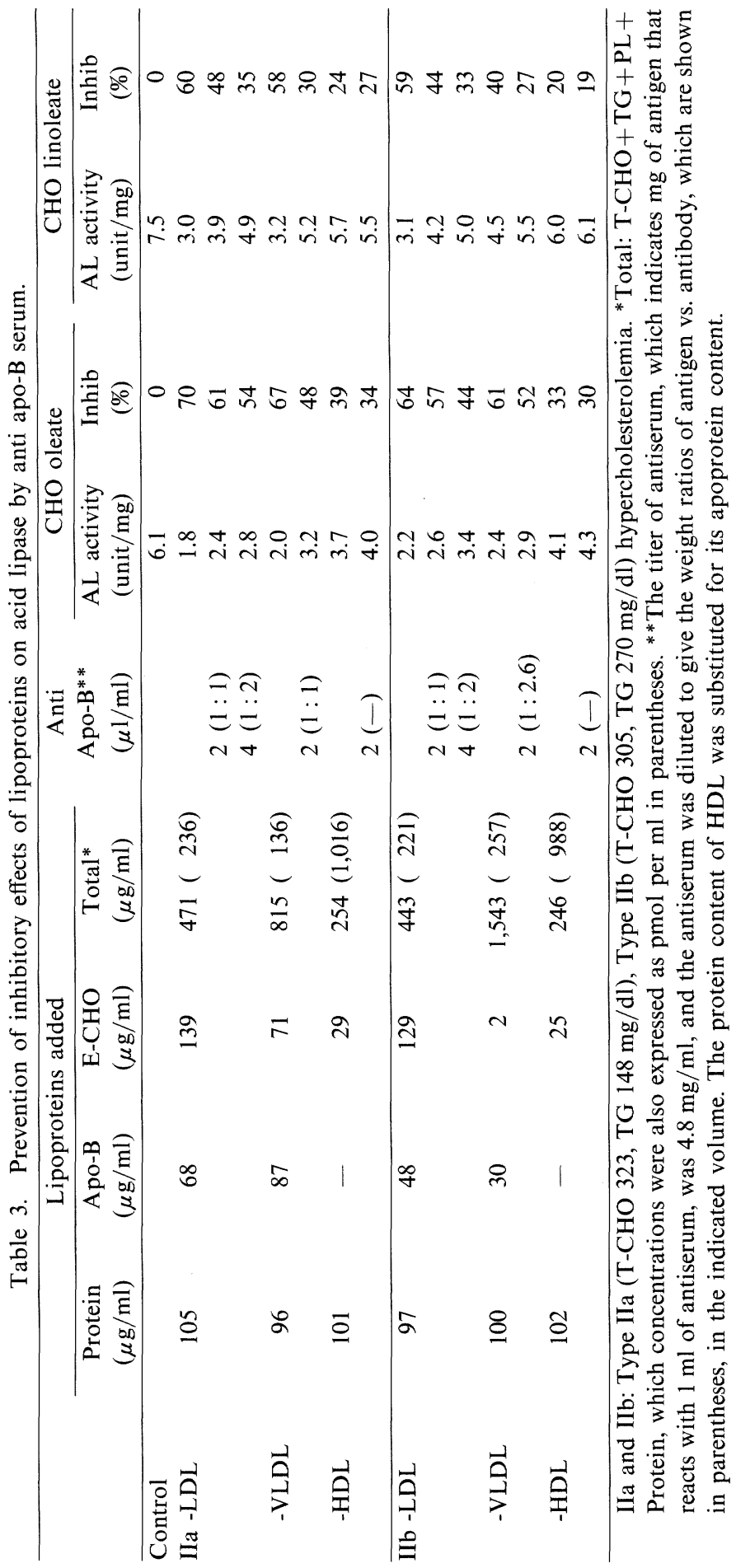

Vol. 11, No. 2, 1991 

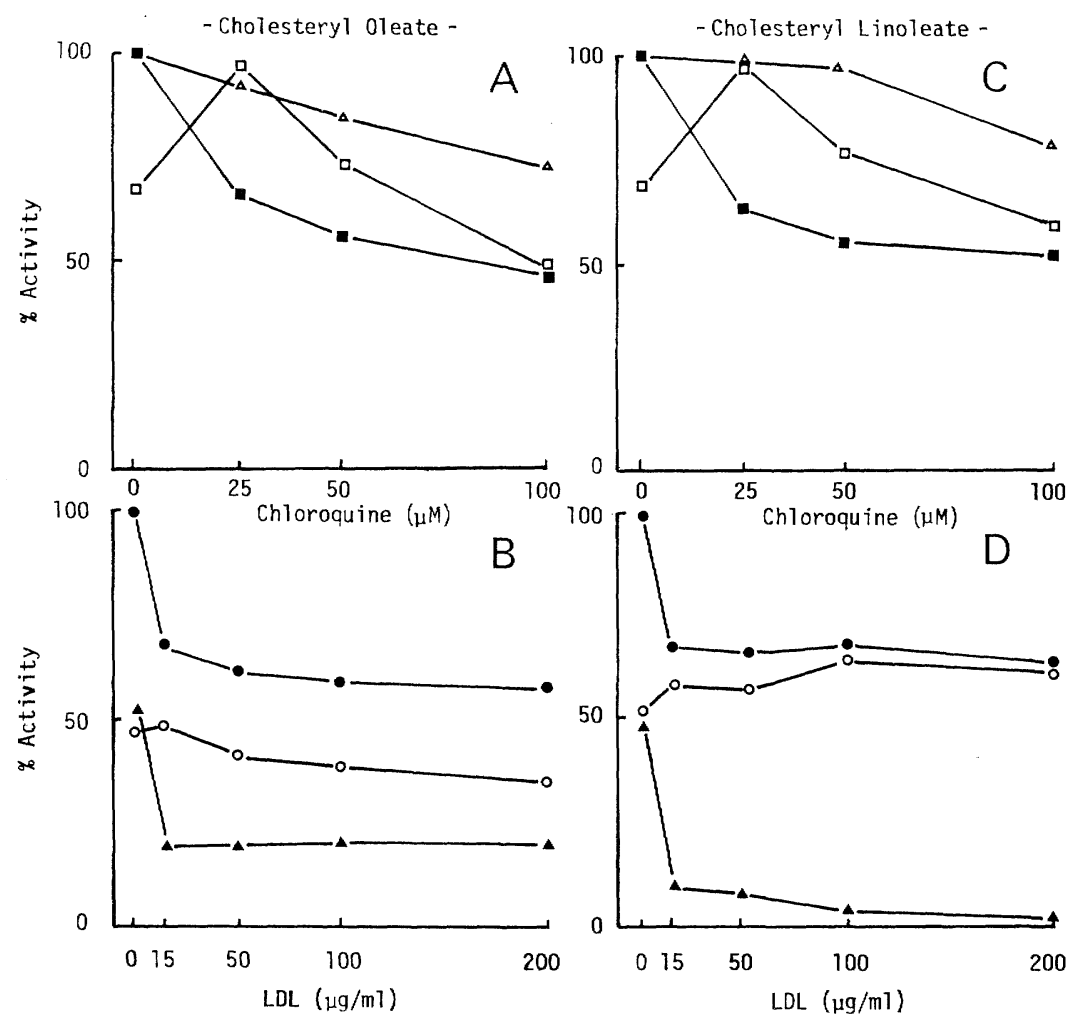

Fig. 3. The inhibitory effect of LDL on the AL hydrolysis of CHO oleate (A and B) and CHO linoleate (C and D) in cultured human MNL. A and C: Effects of increasing concentration of chloroquine are shown in the absence $(\square)$ and presence $(\square)$ of $15 \mu \mathrm{g}$ / $\mathrm{ml} \mathrm{LDL}$, and in the cell-free extract $(\triangle)$. B and D: Effects of an increasing concentration of LDL are illustrated in the absence $(\bullet)$ and presence $(\bigcirc)$ of $100 \mu \mathrm{M}$ chloroquine, and the difference $(\Lambda)$ between these two conditions $(\bullet$ and $\bigcirc)$ represents the \% activity specifically inhibited by chloroquine.

activities in both lysosomes and cytosol (closed circles in Fig. 3 (B), (D)). The inhibition caused by chloroquine, a lysosomotropic agent, was greater for linoleate esters than for oleate esters, as was indicated by the difference between activities in the absence of and in the presence of $100 \mu \mathrm{M}$ chloroquine (closed triangles in Fig. 3 (B), (D)). In other words, most of the activities inhibited by LDL were related to lysosomal fraction for linoleate esters, whereas they were related to both lysosomal and cytosol fractions for oleate esters.

\section{DISCUSSION}

A characteristic feature of the genetic deficiency of lysosomal acid lipase, as seen in Wolman's disease, and cholesterol ester storage disease (CESD) is an intracellular accumulation of E-CHO and TG. By use of fibroblasts isolated from 
CESD, in which there has been reported premature coronary atherosclerotic changes [1], it has been clarified that lysosomal AL plays a major role in hydrolyzing LDL-associated E-CHO entering the cell via specific receptors [12]. In animal studies of atherosclerosis, there have been contradictory reports about the E-CHO-hydrolyzing activity of the aorta. In hypercholesterolemic rabbits that had been fed a high CHO-diet, the E-CHO-hydrolyzing activity was occasionally increased [13]. In this case the lipid metabolism may be in a stage that would compensate for a large influx of blood lipids to the cell, thereby causing production of new primary lysosomes and causing the activity of other lysosomal enzyms to also be high $[13,14]$. In the advanced and chronic stages of hypercholesterolemia with atherosclerotic lesions in the aorta, lipid-laden lysosomes were deficient in lysosomal E-CHO-hydrolyzing activity [15] and other E-CHO hydrolases in microsomes were also decreased [16].

A major factor influencing the point at which compensation turns to dysfunction of the hydrolase activity may be the level of LPO in the blood and aorta. In chronic hypercholesterolemic conditions the LPO levels are often increased $[7,16-$ 18], which increase correlates with the degree of atherosclerotic changes in the aorta $[19,20]$. Since AL is sensitive to oxidation [21, 22], the reduced AL activity in the hypercholesterolemic condition as found in the present and previous [8] studies may be due to an increase of LPO in the cell. Among negative correlations observed between the AL activity and various parameters of the hypercholesterolemic condition, the negative correlation between the AL activity and TBA may be an important finding. Since plasma LPO is associated with the lipid portion of lipoproteins, the prevention by anti apo-B serum of the inhibition of AL activity caused by addition of lipoproteins to the assay system and to the MNL culture medium supports this possibility of LPO involvement. That is, the antiserum may precipitate apo-B-carrying LPO lipoproteins or may interfere with the contact of these lipoproteins with the enzyme molecules. A possible autosomal mutation resulting in reduced enzyme activity has also been suggested by family studies of patients with hypercholesterolemia in which MNL were used [7]. There is evidence that the foam cells found in atherosclerotic lesions are derived from circulating monocytes $[5,23]$. The reduced $\mathrm{AL}$ activity of MNL in hypercholesterolemic individuals may be a useful warning sign that precedes the onset of symptomatic atherosclerosis.

\section{REFERENCES}

1. Cortner, J.A., Coates, P.M., Swoboda, E., and Schnatz, J.D. (1976): Genetic variation of lysosomal acid lipase. Pediatr. Res., 10, 927-932.

2. Maehira, F., Nakada, F., and Hokama, T. (1984): Characteristics of acid esterase in Wolman's disease. Biochem. Med., 32, 322-330.

3. Castelli, W.P., Garrison, R.J., and Wilson, P.W.F. (1986): Incidence of coronary artery disease and lipoprotein cholesterol levels. JAMA, 256, 2835-2838.

4. Fredrickson, D.S., and Levy, R.I. (1972): Familial hyperlipoproteinemias, in The Metabolic

Vol. 11, No. 2, 1991 
Basis of Inherited Disease, ed. by Stanbury, J.B., McGraw-Hill, New York, pp. 545-614.

5. Mahley, R.W. (1982): Atherogenic hyperlipoproteinemia. Med. Clin. North Am., 66, 375402.

6. Hagemenas, F.C., Manaugh, L.C., Illingworth, D.R., Sundbery, E.E., and Yatsu, F.M. (1984): Cholesteryl ester hydrolase activity in mononuclear cells from patients with type II hypercholesterolemia. Atherosclerosis, 50, 335-344.

7. Coates, P.M., Langer, T., and Cortner, J.A. (1986): Genetic variation of human mononuclear leukocyte lysosomal acid lipase activity. Relationship to atherosclerosis. Atherosclerosis, 62, 11-20.

8. Maehira, F., Miyagi, I., Nagamine, J., and Kohno, S. (1990): Reversible inhibitory effects of apo-B-carrying lipoproteins on acid lipase activity of mononuclear leukocytes from cholesterol-fed rabbits. J. Clin. Biochem. Nutr., 9, 103-114.

9. Belfrage, P., and Vaughan, M. (1969): Simple liquid-liquid partition system for isolation of labeled oleic acid from mixtures with glycerides. J. Lipid Res., 341-344.

10. Yagi, K. (1976): A simple fluorometric assay for lipoperoxide in blood plasma. Biochem. Med., 15, 212-216.

11. Lowry, O.H., Rosebrough, N.J., Farr, A.L., and Randall, R.J. (1951): Protein measurement with the Folin phenol reagent. J. Biol. Chem., 183, 265-275.

12. Goldstein, J.L., Dana, S.E., Faust, J.R., Beaudet, A.L., and Brown, M.S. (1975): Role of lysosomal acid lipase in the metabolism of plasma low density lipoprotein. J. Biol. Chem., 250, 8487-8494.

13. Brecher, P., Pyun, H.Y., and Chobanian, A.V. (1977): Effect of atherosclerosis on lysosomal cholesterol esterase activity in rabbit aorta. J. Lipid Res., 18, 154-163.

14. Morisaki, M., Murano, S., Shinomiya, M., Sasaki, N., Shirai, K., Matsuoka, N., Mizobuchi, M., Akikusa, B., Saito, Y., and Kumagai, A. (1982): Lipid metabolism in arteriosclerotic arterial wall of rats. Atherosclerosis, 43, 51-57.

15. Takano, T., and Imanaka, T. (1978): Lysosomal acid cholesteryl esterase and atherosclerosis in cholesterol-fed rabbits. Acta Histochem. Cytochem., 11, 323-336.

16. Shirai, K., Matsuoka, N., Morisaki, N., Murano, S., Sasaki, N., Shinomiya, M., Saito, Y., Kumagai, A., and Mizobuchi, M. (1980): Effect of tocopherol deficiency on lipid metabolism in the arterial wall of rats on normal and high cholesterol diets. Artery, 6, 484-506.

17. Domagala, B., Hartwich, J., and Szczeklik, A. (1989): Hypercholesterolemia and hypertriglyceridemia. Wien. Klin. Wochenschr., 101, 425-428.

18. Wang, J., Zhen, E., Guo, Z., and Yongcai, L. (1989): Effect of hyperlipidemic serum on lipid peroxidation, synthesis of prostacyclin and thromboxane by cultured endotherial cells: Protective effect of antioxidants. Free Radical Biol. Med., 7, 243-249.

19. Glavind, J., Hartmann, S., Clemmesen, J., Jessen, K.E., and Dam, H. (1952): Studies on the role of lipoperoxides in human pathology II. The presence of peroxidized lipids in the atherosclerotic aorta. Acta Pathol. Microbial. Scand., 30, 1-6.

20. Prasad, K., and Kalra, J. (1989): Experimental atherosclerosis and oxygen free radicals. Angiology, 40, 835-843.

21. Rindler-Ludwig, R., Patsch, W., Sailer, S., and Braunsteiner, H. (1977): Characterization and partial purification of acid lipase from human leukocytes. Biochim. Biophys. Acta, 488, 294-304.

22. Brown, W.J., and Sgoutas, D.C. (1980): Purification of rat liver lysosomal cholesterol ester hydrolase. Biochim. Biophys. Acta, 617, 305-317.

23. Brown, M.S., and Goldstein, J.L. (1983): Lipoprotein metabolism in macrophage: Implications for cholesterol deposition in atherosclerosis. Annu. Rev. Biochem., 52, 223-261. 